\title{
Efeitos Colaterais a longo prazo associados ao uso de Anticoncepcionais Hormonais Orais
}

\section{Long-term side effects associated with the use of Oral Hormonal contraceptives}

Kamila Cardoso Jurema ${ }^{1}$, Halline Cardoso Jurema².

\section{RESUMO}

Os anticoncepcionais hormonais orais são métodos contraceptivos eficazes que impedem a ocorrência de gravidezes indesejadas. São classificados quanto a composição hormonal como combinados e minipílulas e não diferente dos demais medicamentos, esses também geram efeitos colaterais. Dessa forma, o objetivo dessa pesquisa foi delinear os efeitos colaterais relacionados ao uso contínuo e a longo prazo de anticoncepcionais hormonais orais. Trata-se de uma Revisão Integrativa realizada com base em artigos publicados entre os anos de 2015 e 2021, nas bases de dados MEDLINE, BDENF, LILACS e o Google Scholar. Entre os resultados encontrados evidenciou-se que os anticoncepcionais hormonais orais podem acarretar danos maiores a saúde, como trombose, aumento da pressão arterial, problemas cardiovasculares, neoplasias, principalmente com o uso a longo prazo. Conclui-se que é necessário que os profissionais de saúde, especialmente os farmacêuticos, e as mulheres estejam em alerta, quanto aos efeitos colaterais desencadeados pelo uso prolongado do método hormonal oral e os agravos destes quando associados a predisposições de risco modificáveis e não modificáveis pertinentes a saúde das mulheres.

Palavras-chave: Anticoncepcionais Orais Hormonais. Efeitos Colaterais e Reações Adversas Relacionados a Medicamentos. Contraceptivos Hormonais. Assistência Farmacêutica.

\section{ABSTRACT}

Oral hormonal contraceptives are effective contraceptive methods that prevent unwanted pregnancies from occurring. They are classified according to a hormonal composition as combinations and mini pills and not different from the other drugs, these also have associated effects. Thus, the objective of this research was to outline the effects related to the continuous and long-term use of oral hormonal contraceptives. This is an Integrative Review carried out based on articles published between the years 2015 and 2021, in the databases MEDLINE, BDENF, LILACS and Google Scholar. Among the results found, it was shown that oral contraceptive hormones can cause greater damage to health, such as thrombosis, increased blood pressure, cardiovascular problems, neoplasms, especially with long-term use. It is concluded that it is necessary that health professionals, especially pharmacists, and visual women on alert, regarding the effects triggered by the prolonged use of the oral hormonal method and the aggravations of these when associated with modifiable and non-modifiable risk predispositions. Relevant to women's health.

Keywords: Contraceptives, Oral, Hormonal. Drug-Related Side Effects and Adverse Reactions. Contraceptive Agents, Hormonal. Pharmaceutical Services.
${ }^{1}$ Graduanda do curso de Farmácia, da Universidade de Gurupi - UnirG.

E-mail: kamilacj2015@gmail.com

${ }^{2}$ Enfermeira. Pós-graduada em Ginecologia e Obstetrícia pela Faculdade Venda Nova do Imigrante (FAVENI). 


\section{INTRODUÇÃO}

Os anticoncepcionais hormonais orais são as formas de contracepção mais utilizadas no mundo, por serem reversíveis e eficientes na prevenção de gravidezes indesejadas (COUTO et al., 2020).

Esse método é assim denominado por possuir em sua composição os hormônios estrogênio e progestagênio, responsáveis pelo mecanismo de ação do medicamento que é impedir a ovulação, podendo esses serem encontrados em associação ou isolados (ALMEIDA; ASSIS, 2017). Os anticoncepcionais chamados combinados são compostos pela associação dos dois hormônios, estrogênio e progestagênio, e os isolados denominados minipílulas, possuem em sua composição unicamente o progestagênio.

O mecanismo de ação consiste na alteração do eixo neuroendócrino, impedindo que alcance o pico do hormônio luteinizante (LH) que é encarregado pela ovulação gerando assim um bloqueio gonadotrófico, sendo esse o principal efeito. Além deste, há efeitos adicionais que dificultam a concepção, como o aumento da consistência do muco cervical obstando a entrada do espermatozoide e a hipotrofia endometrial, perdendo as condições para a implantação do embrião e a diminuição dos movimentos das trompas. A junção desses mecanismos de ação determina a eficácia do método (OLIVEIRA et al., 2019; FINOTTI, 2015).

A comercialização dessa contracepção foi aprovada em 1960 nos Estados Unidos, logo em seguida, o que mais tarde, levou ao uso expandido em todo o mundo, como uma forma de controle e estratégia de planejamento familiar pelos serviços de saúde, voltado para as mulheres. No Brasil, a comercialização dos anticoncepcionais teve o seu início por volta de 1962, sendo dispensadas de forma gratuita por prescrição médica por volta de 1965 (SILVA, 2017).

No Brasil, há estimativas que apontam que cerca de $23 \%$ das mulheres em idade reprodutiva utilizam anticoncepcionais hormonais orais (OLIVEIRA et al., 2019). Nos países desenvolvidos aproximadamente $18 \%$ das mulheres, casadas ou não, fazem uso desses métodos contraceptivos, em contrapartida, nos países em desenvolvimento, são cerca de $75 \%$ das mulheres (ALMEIDA; ASSIS, 2017).

$O$ uso de qualquer medicação, incluindo os anticoncepcionais, trazem consigo o aparecimento de efeitos indesejados. Os efeitos colaterais frequentemente associados a essa classe de medicamentos, segundo Almeida e Assis (2017), são dores de cabeça, 
náuseas, êmeses, irritabilidade, dorsalgia, maior apetite com resultante aumento de peso, queda de cabelo e alterações na libido.

De acordo com Finotti (2015), em escala de importância, os principais efeitos adversos são as náuseas, sangramento inesperado, mastalgia, cefaleia, ganho de peso e acne, além de frisar a ocorrência de complicações cardiovasculares, que mesmo raras, significam o risco mais temível para mulheres que fazem seu uso, focalizando no tromboembolismo venoso, o Infarto Agudo do Miocárdio (IAM) e o Acidente Vascular Cerebral (AVC).

Mulheres propensas às doenças cardiovasculares e que fazem 0 uso de anticoncepcionais hormonais tem mostrado possuir maior disposição para a Trombose Arterial (COUTO et al., 2020). As contraindicações para a utilização desses medicamentos podem intensificar ou gerar efeitos colaterais, sendo necessário, a avaliação detalhada da paciente para evitar possíveis agravos.

O profissional farmacêutico tem relevante importância na orientação as pacientes, com a finalidade de evitar a descontinuação do uso do anticoncepcional de forma inadequada, informando haver a possibilidade de troca de medicação ou método, esclarecendo as dúvidas e informando quanto aos efeitos colaterais existentes desde os comuns aos raros, principalmente, aqueles relacionados ao uso prolongado, visto que a mesma deve estar ciente e esclarecida dos possíveis efeitos.

Diante do exposto, esse estudo objetiva assim delinear os efeitos colaterais relacionados ao uso contínuo e à longo prazo de anticoncepcionais hormonais orais.

\section{MATERIAIS E METODOS}

A presente Revisão Integrativa da Literatura foi dirigida a partir da seguinte pergunta norteadora: "Quais agravos a saúde da mulher, os anticoncepcionais hormonais orais podem desencadear com o uso contínuo e a longo prazo?"

Para responder à essa pergunta, foi realizado um levantamento de artigos nas bases de dados eletrônicas, no dia 30 de março de 2021, sendo elas: o Sistema Online de Busca e Análise de Literatura Médica (MEDLINE); Banco de Dados em Enfermagem (BDENF); Literatura Latino-americana e do Caribe em Ciências da Saúde (LILACS) e o Google Scholar, com o intuito de selecionar artigos científicos conexos ao tema.

Procedeu-se o cruzamento dos descritores relacionados ao tema investigado: Anticoncepcionais Orais Hormonais AND Efeitos Colaterais e Reações Adversas Relacionados a Medicamentos; Contraceptivos Hormonais AND Assistência Farmacêutica. 
Os critérios de inclusão foram estudos publicados entre 2015 a 2021; no idioma português; disponíveis em texto completo, de forma gratuita; que respondessem à questão norteadora e ao objetivo de pesquisa. Já os critérios de exclusão foram os estudos duplicados nas bases de dados; fora do recorte temporal delimitado; que não respondiam à questão e ao objetivo da pesquisa; além dos estudos não publicados em periódicos científicos.

$\mathrm{Na}$ busca online através dos descritores, foram identificados 11.206 artigos, após aplicar o filtro de texto completo restaram 8.945 artigos. Em seguida, aplicou-se o filtro de idioma português restando 3.340 artigos. Aplicando o intervalo temporal de 2015 a 2021 restaram 11 artigos, que foram lidos na íntegra. Destes, encontrou-se 1 estudo fora do objetivo, onde o mesmo estava em duplicidade, sendo assim, foram excluídos 2 artigos, restando 9 artigos científicos para a apresentação dos resultados e discussão desta revisão.

Figura 1. Fluxograma de seleção dos estudos para a pesquisa.

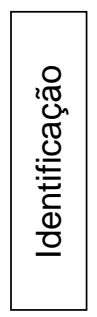

11.206 artigos identificados por meio das bases de dados MEDLINE, LILACS, BDENF, Google Acadêmico.

Texto completo Idioma português Publicados entre 2015 a 2021

Estudos Finais

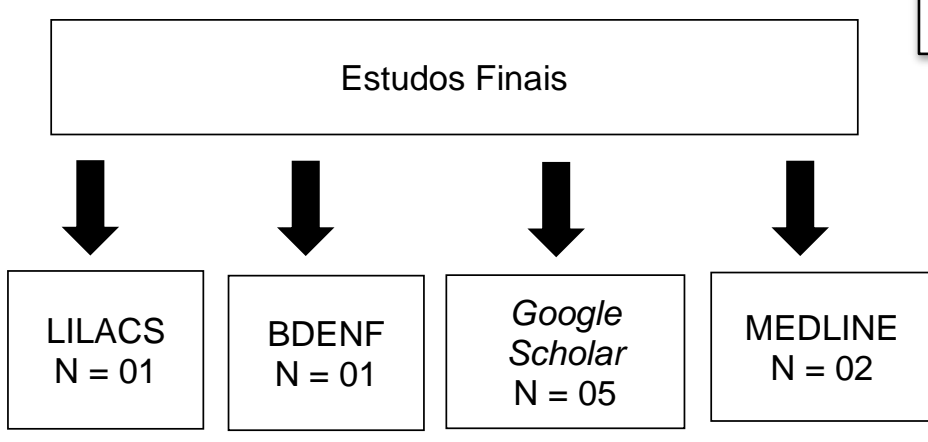

Excluídos nesta fase: 11.195 artigos

Análise dos artigos completos

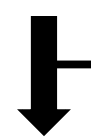

11 estudos restantes Exclusão por: - Não integrarem a questão e o objetivo do estudo.

- Duplicados.

Fonte: Autora da pesquisa. 


\section{RESULTADOS}

A escolha do tema abordado está vinculada a necessidade de mais informações ao público, aos profissionais de saúde, e principalmente, os farmacêuticos. A seleção de artigos científicos mais recentes se deu pela relevância de abranger o assunto através de estudos atualizados e com correções de estudos anteriores.

Além de evidenciar as atualizações pertinentes a Classe Farmacológica dos Anticoncepcionais e os efeitos colaterais que se fazem frequentes nas pacientes que os utilizam.

A partir dos resultados encontrados, foram analisadas e comparadas as alegações utilizadas pelos autores dos artigos e, suas evidências científicas sobre os efeitos colaterais desencadeados pelo uso contínuo de Anticoncepcionais Hormonais Orais.

Quadro 1 - Para organização desses estudos, os resultados foram categorizados de forma descritiva, sendo analisados com embasamento literal, em conformidade com o tema, trazendo os seguintes dados: título, autores, ano de publicação, objetivo e os tipos de pesquisas.

\begin{tabular}{|c|c|c|c|}
\hline TÍTULO & AUTORES/ANOS & OBJETIVO & TIPOS DE PESQUISA \\
\hline $\begin{array}{c}\text { Evidências dos } \\
\text { efeitos adversos no } \\
\text { uso de } \\
\text { anticoncepcionais } \\
\text { hormonais orais em } \\
\text { mulheres. }\end{array}$ & $\begin{array}{l}\text { COUTO et al., } \\
2020\end{array}$ & $\begin{array}{c}\text { Identificar na literatura as } \\
\text { evidências científicas sobre os } \\
\text { eventos adversos, oriundos do } \\
\text { uso de anticoncepcional hormonal } \\
\text { oral por mulheres. }\end{array}$ & $\begin{array}{l}\text { Revisão integrativa de } \\
\text { Literatura. }\end{array}$ \\
\hline $\begin{array}{l}\text { Efeitos colaterais e } \\
\text { alterações } \\
\text { fisiológicas } \\
\text { relacionadas ao uso } \\
\text { contínuo de } \\
\text { anticoncepcionais } \\
\text { hormonais orais. }\end{array}$ & $\begin{array}{c}\text { ALMEIDA; } \\
\text { ASSIS, } 2017 .\end{array}$ & $\begin{array}{c}\text { Avaliar as alterações fisiológicas, } \\
\text { os efeitos colaterais e as reações } \\
\text { adversas que se relacionam ao } \\
\text { uso de anticoncepcionais } \\
\text { hormonais orais. }\end{array}$ & $\begin{array}{l}\text { Revisão Bibliográfica do tipo } \\
\text { sistemática. }\end{array}$ \\
\hline $\begin{array}{c}\text { Prevalência dos } \\
\text { efeitos colaterais } \\
\text { pelo uso de } \\
\text { anticoncepcionais } \\
\text { orais em estudantes } \\
\text { de medicina de uma } \\
\text { instituição privada. }\end{array}$ & $\begin{array}{l}\text { CABRAL et al., } \\
2018 .\end{array}$ & $\begin{array}{c}\text { Investigar a prevalência dos } \\
\text { efeitos colaterais do uso de } \\
\text { anticoncepcionais oral em } \\
\text { mulheres que estudam na } \\
\text { Faculdade de Medicina de Olinda } \\
\text { (FMO). }\end{array}$ & $\begin{array}{c}\text { Estudo transversal, clínico, } \\
\text { prospectivo, observacional e } \\
\text { descritivo, com } 212 \text { estudantes } \\
\text { do sexo feminino da Faculdade } \\
\text { de Medicina de Olinda. }\end{array}$ \\
\hline $\begin{array}{l}\text { Saberes e práticas } \\
\text { sobre o uso do } \\
\text { contraceptivo } \\
\text { hormonal oral por } \\
\text { mulheres em idade } \\
\text { fértil. }\end{array}$ & $\begin{array}{l}\text { HAERTEL et al., } \\
2020 .\end{array}$ & $\begin{array}{l}\text { Conhecer os saberes e as } \\
\text { práticas de uso do contraceptivo } \\
\text { hormonal oral por mulheres em } \\
\text { idade fértil usuárias de uma } \\
\text { unidade básica de saúde da } \\
\text { família. }\end{array}$ & $\begin{array}{l}\text { Pesquisa qualitativa, } \\
\text { exploratória e descritiva } \\
\text { realizada em um município do } \\
\text { sul do Brasil com } 15 \text { mulheres } \\
\text { em idade fértil usuárias de } \\
\text { contraceptivo hormonal oral. }\end{array}$ \\
\hline
\end{tabular}




\begin{tabular}{|c|c|c|c|}
\hline $\begin{array}{c}\text { Métodos } \\
\text { contraceptivos: } \\
\text { Principais riscos e } \\
\text { efeitos adversos. }\end{array}$ & LUZ et al., 2021. & $\begin{array}{l}\text { Demonstrar quais os principais } \\
\text { riscos e efeitos adversos dos } \\
\text { métodos contraceptivos, } \\
\text { mostrando quais faixas etárias } \\
\text { apresentam maiores riscos, quais } \\
\text { métodos são mais bem aceitos } \\
\text { pelas mulheres bem como os que } \\
\text { apresentam maior segurança. }\end{array}$ & $\begin{array}{l}\text { Revisão de Literatura, de } \\
\text { caráter descritivo e exploratório. }\end{array}$ \\
\hline $\begin{array}{l}\text { Conhecimento sobre } \\
\text { os efeitos dos } \\
\text { contraceptivos } \\
\text { hormonais por } \\
\text { acadêmicas da } \\
\text { saúde }\end{array}$ & $\begin{array}{l}\text { BORGES et al., } \\
2016 .\end{array}$ & $\begin{array}{l}\text { Identificar o conhecimento de } \\
\text { acadêmicas da saúde sobre os } \\
\text { efeitos colaterais relacionados à } \\
\text { sexualidade causados por } \\
\text { métodos contraceptivos orais. }\end{array}$ & $\begin{array}{c}\text { Estudo quantitativo, descritivo, } \\
\text { exploratório e prospectivo com } \\
262 \text { acadêmicas de Cursos de } \\
\text { Graduação em Enfermagem } \\
\text { Medicina da na Faculdade de } \\
\text { Medicina de São José do Rio } \\
\text { Preto-SP. }\end{array}$ \\
\hline $\begin{array}{c}\text { Influência de } \\
\text { anticoncepcionais } \\
\text { hormonais e } \\
\text { ocorrência de } \\
\text { acidente vascular } \\
\text { cerebral: revisão } \\
\text { integrativa. }\end{array}$ & LIMA et al., 2017. & $\begin{array}{l}\text { Identificar evidências científicas } \\
\text { acerca da influência do uso de } \\
\text { anticoncepcionais hormonais na } \\
\text { ocorrência do acidente vascular } \\
\text { cerebral (AVC). }\end{array}$ & $\begin{array}{l}\text { Revisão Integrativa da } \\
\text { Literatura. }\end{array}$ \\
\hline $\begin{array}{l}\text { Efeitos dos } \\
\text { diferentes } \\
\text { anticoncepcionais } \\
\text { hormonais nos } \\
\text { valores de pressão } \\
\text { arterial da mulher. }\end{array}$ & $\begin{array}{l}\text { RIBEIRO et al., } \\
2018 .\end{array}$ & $\begin{array}{l}\text { Identificar na literatura evidências } \\
\text { sobre a relação entre o uso de } \\
\text { diferentes métodos } \\
\text { anticoncepcionais hormonais e as } \\
\text { alterações nos valores de } \\
\text { pressão arterial em mulheres. }\end{array}$ & $\begin{array}{l}\text { Revisão Integrativa da } \\
\text { Literatura. }\end{array}$ \\
\hline $\begin{array}{l}\text { Proteína C Reativa } \\
\text { em Usuárias de } \\
\text { Contraceptivo Oral: } \\
\text { Fatores } \\
\text { Relacionados e } \\
\text { Risco } \\
\text { Cardiovascular. }\end{array}$ & $\begin{array}{l}\text { SANTOS et al., } \\
2016 .\end{array}$ & $\begin{array}{c}\text { Revisar trabalhos que } \\
\text { investigaram os níveis da PCR } \\
\text { em usuárias de COC, bem como } \\
\text { descrever os fatores envolvidos } \\
\text { nesta associação. }\end{array}$ & $\begin{array}{l}\text { Revisão Sistemática da } \\
\text { Literatura. }\end{array}$ \\
\hline
\end{tabular}

Fonte: Autora da Pesquisa. 


\section{DISCUSSÃO}

Os resultados obtidos através da análise dos artigos evidenciaram que os efeitos colaterais são motivacionais para o abandono dos anticoncepcionais hormonais orais, além das evidências e estudos apontarem para danos maiores a saúde, como trombose, aumento da pressão arterial, problemas cardiovasculares, neoplasias, principalmente com o uso a longo prazo, além de outros efeitos menores que serão abordados.

Segundo Couto et al., (2020), os contraceptivos hormonais orais a longo prazo podem ocasionar Trombose Venosa Periférica (TVP) na mulher, mas esse risco não é comum a todas que fazem o uso desses fármacos, pois há uma associação do risco com as predisposições da paciente, fatores estes que muitos são considerados critérios de contraindicação, como idade $\geq 35$ anos, hipertensão, tabagismo, doenças hormonais, prédisposição à trombose e eventos vasculares.

Couto et al., (2020), afirmam que os anticoncepcionais hormonais do tipo combinados, alteram a Pressão Arterial (PA) pelo etinilestradiol (EE), que acentua a produção de angiotensinogênio hepático, elevando a PA através do Sistema Renina-AngiotensinaAldosterona (SRAA). Sendo esse o motivo de evitar-se o seu uso em mulheres hipertensas.

Couto et al., (2020), relatam haver estudos controversos quanto ao risco de o uso do anticoncepcional oral provocar Acidente Vascular Cerebral (AVC). Já para a associação de anticoncepcionais orais nas clientes com neoplasia mamária, há evidências de dependência hormonal do câncer de mama, onde a reposição hormonal combinada e o câncer de mama mostram um aumento do risco.

No estudo de Almeida e Assis (2017), os autores afirmaram que as mulheres com predisposição a enfermidades cardiovasculares e que fazem uso de anticoncepcionais hormonais apresentam risco maior para trombose arterial e que há ainda casos de trombose mesentérica e venosa. A justificativa que os autores trazem é baseada na dose do estrogênio, visto que o EE gera ampliação no desenvolvimento da trombina, elevando os fatores de coagulação.

Para o risco de Acidente Vascular Encefálico (AVE), Almeida e Assis (2017) relatam casos associados com os anticoncepcionais, porém, o risco é diminuído quando se tem baixa dosagem de estrogênio. Quanto ao câncer de mama, Almeida e Assis (2017) afirmam que nem todos são dependentes de hormônios, e que não se pode confirmar uma direta relação deste com o anticoncepcional hormonal oral, contrariando a afirmação feita por Couto et al., (2020). 
$\mathrm{Na}$ pesquisa desenvolvida por Cabral et al., (2018), realizada na Faculdade de Medicina de Olinda com 212 mulheres, destas 58\% não usavam anticoncepcional oral e $42 \%$ faziam uso deste. Cabral et al., (2018), descrevem que os efeitos colaterais são relacionados, sobretudo, com a dose do EE. Os efeitos relatados foram cefaleia, mudança no humor, aumento do peso, retenção hídrica, redução da libido, escape e sensibilidade mamária. As mulheres que utilizavam a dosagem de 15 mcg relataram não haver efeitos colaterais, já com dosagem superior a isso foram descritos tais efeitos.

Haertel et al., (2020), realizaram uma pesquisa em uma Unidade Básica de Saúde (UBS) com 15 participantes que faziam o uso de anticoncepcionais. Quanto aos efeitos colaterais, as mulheres demonstram possuir conhecimento de que o medicamento desencadeia efeitos que podem ser maléficos a saúde, como exemplo uma entrevistada afirmou ter consciência de que o método pode desencadear trombose e os autores confirmam no estudo que há evidências desse efeito colateral mesmo que raramente.

Uma dúvida importante de uma entrevistada sobre sangramento foi relatada na pesquisa de Haertel et al., (2020), que a caracterizaram como uma dúvida frequente que é pouco informada por profissionais, sendo um efeito comum e que gera grande índice de abandono do método. Cabendo ao profissional investigar a causa do sangramento para melhor orientar a paciente, visto que o mesmo pode ser desencadeado por exemplo por uso inadequado.

Os efeitos colaterais citados pelas entrevistadas que participaram do estudo de Haertel et al., (2020) foram aumento de peso, inchaço, dor de cabeça, enxaqueca, perca da libido, espinhas, cólicas, mal estar, e um relato preocupante de perca dos sentidos dos membros inferiores de uma entrevistada fumante, os autores abordam no estudo a contraindicação de anticoncepcionais por mulheres tabagistas principalmente por riscos cardiovasculares.

Vale enfatizar que há contraindicação para mulheres que fazem o uso $\geq 15$ cigarros por dia, pelo risco de doença cardiovascular arterial, além da contraindicação do uso de anticoncepcionais em casos de enxaqueca especialmente com aura, devido ao maior risco de AVC, devendo-se suspender o uso especialmente se houverem fatores adicionais a esses (FINOTTI, 2015).

Luz et al., (2021), afirmaram que usar anticoncepcionais possuindo algumas patologias como hipertensão arterial pode aumentar o risco de AVE e IAM. Luz et al., (2021), descrevem que as usuárias de contraceptivos orais combinados expunham maior risco IAM ou AVE isquêmico ao se comparar com as não usuárias, porém a variação se 
dava pela dose do estrogênio sendo essa proporcional ao risco e sem relação expressa com o tipo e dosagem do progestagênio.

Apesar de os anticoncepcionais hormonais combinados corroborarem elevando a possibilidade de eventos trombóticos arteriais e venosos, Luz et al., (2021), abordam que existe um baixo risco estando relacionado a fatores além da medicação. Já em relação ao padrão de sangramento e controle do ciclo, a dosagem mais baixa se mostrou ser mais favorável para os anticoncepcionais orais compostos de estetrol e drospirenona refletindo uma menor frequência ou falta de sangramento fora do planejado, além de provocar menos efeitos adversos se comparado a composição de estetrol com levonorgestrel.

Em uma avaliação realizada na pesquisa de Luz et al., (2021), concluíram que a predominância de efeitos adversos pelo uso prolongado e ininterrupto de contraceptivos orais é alta. E que mesmo seguros podem apresentar riscos pela junção de outros fatores, mas com pequena taxa de ocorrência.

Borges et al., (2016), em sua pesquisa com 262 acadêmicas de enfermagem e medicina da Faculdade de Medicina de São José do Rio Preto, demonstrou que 199 acadêmicas faziam uso do anticoncepcional oral ou outro método hormonal, 66,8\% apresentaram um ou mais efeitos colaterais e $61,5 \%$ fazem uso por um período de 1 a 5 anos.

Os efeitos relatados e identificados no estudo de Borges et al., (2016), em ordem do mais frequente para o menos frequente foram alteração do fluxo menstrual, sensibilidade mamária, cefaleia, sangramentos fora do ciclo, alteração de peso, cólica, náusea/vômito, aumento da mama, baixa na libido, distúrbio gastrointestinal, acne, vertigens e vaginite.

Borges et al., (2016), relatam ser um grande motivo de descontinuidade do método o aparecimento frequente de efeitos adversos, e os mesmos relatados pelas acadêmicas são bastante evidentes em outros estudos relatados anteriormente, fazendo-se necessário muita das vezes a troca do método.

Lima et al., (2017), discorreram em seu estudo que o EE induz alterações expressivas no sistema de coagulação, ocasionando a ampliação de trombina e fatores de coagulação, além de diminuir os inibidores fisiológicos da coagulação, tais alterações acarretam em eventos trombolíticos como AVC, que se faz mais evidente em pacientes que já possuem fatores de risco.

Ainda segundo Lima et al., (2017), concluiu-se que há maior risco de AVC em mulheres que utilizam anticoncepcional oral combinado. Observou-se que nas novas associações continuam notando que há provocação do AVC, independente da dose, 
embora doses maiores exponham maiores chance de AVC. Já sobre o tempo de uso, o risco se mostrou maior na utilização atual do que na quantidade de anos que foi feito o uso.

As condições clínicas da mulher também são evidenciadas por Lima et al., (2017), como fator de aumento ao risco de AVC. Os autores reforçam a necessidade de acompanhamento profissional para evitar principalmente o uso de anticoncepcionais em casos contraindicados como principalmente em casos de diabetes, hipertensão arterial, histórico familiar trombolítico que podem desencadear tal evento.

Segundo Ribeiro et al., (2018), anticoncepcionais hormonais combinados alteram a PA principalmente por modificar o SRAA causando a retenção de água e sódio, sendo contraindicados para hipertensas.

Ribeiro et al., (2018), notaram em seu estudo que mesmo com a mudança na dose do EE dos novos anticoncepcionais, os efeitos sobre a PA permanecem sendo vistos.

Ribeiro et al., (2018), relatam que a introdução do progestagênio drospirenona para neutralizar a indução do SRAA causada pelo estrogênio EE e bloquear os receptores de testosterona, gera benefícios quanto a PA, porém a combinação aumenta-se o risco de efeitos trombóticos principalmente quando se há predisposição, fazendo-se assim necessária uma anamnese completa para se escolher o melhor método.

Santos et al., (2016), relatam haver avanço de padrões inflamatórios da Proteína C Reativa (PCR) em mulheres saudáveis em idade reprodutiva que fazem uso de anticoncepcional oral combinado e tal evento aumenta o risco de doenças cardiovasculares e metabólicas.

No estudo desenvolvido por Santos et al., (2016), mostraram que usuárias de anticoncepcional combinado possuíam a PCR 3 vezes maior que mulheres obesas sem 0 uso da medicação já que a obesidade é a principal causa de variação da PCR. A ingestão prolongada de EE e progestina indicavam alterar a PCR, sendo a elevação desta proporcional ao tempo de uso. Além dos hormônios estrogênios causarem tal alteração, a baixa na sensibilidade a insulina causada pelo progestagênio também pode desencadear mudanças metabólicas que aumenta a PCR preconizando assim maior risco cardiovascular.

A atuação do médico e/ou enfermeiro e/ou farmacêutico é de suma importância, para evitar que o uso do anticoncepcional seja feito por pacientes com critérios de contraindicação relevantes, que podem acarretar em danos graves a saúde. Esses critérios podem desenvolver-se por alterações no organismo sendo assim necessário o contínuo acompanhamento médico, esses também podem ser desconhecidos pelas pacientes no 
momento da automedicação assim sendo válida a orientação farmacêutica ou ainda podem passar despercebidos no momento da anamnese deste modo faz-se fundamental o acompanhamento pelo profissional de enfermagem.

Além disso, devem ser constantes os esforços para que a atuação do profissional farmacêutico seja voltada para a avaliação e acompanhamento da farmacoterapia da paciente, para assim, identificar possíveis interações, efeitos colaterais, uso incorreto da medicação, falta de adesão ao método contraceptivo e avaliação de riscos que podem existir associados a medicação.

É importante que as mulheres que utilizam métodos contraceptivos estejam satisfeitas e adaptadas ao método utilizado, seja ele hormonal oral ou outro, visto que o descontentamento e a não adaptação por efeitos colaterais ou a não adesão a rotina, podem levar ao abandono do mesmo, sendo assim desfavorável.

\section{CONSIDERAÇOEES FINAIS}

Foi evidenciado que o uso de anticoncepcionais hormonais orais pode culminar em agravos a saúde da mulher, principalmente, devido ao uso constante e a longo prazo destes fármacos. Quando associados a fatores de riscos modificáveis como o tabagismo e obesidade, e a fatores não modificáveis, como o histórico de eventos trombolíticos, Hipertensão Arterial, Diabetes, enxaqueca com aura, entre outros, esses riscos se fazem mais expressivos.

Os estudos evidenciaram que a relação das patologias crônicas, tais como, o AVE, IAM, aumento da pressão arterial, trombose e câncer mamário, com o uso de anticoncepcionais hormonais orais, ainda apresentam muitas contradições se há ou não associação quanto a ocorrência de efeitos adversos severos, fazendo-se necessário maiores investigações.

Cabe a equipe multiprofissional, em especial o farmacêutico, orientarem as pacientes quanto aos riscos e benefícios expressos em cada método, principalmente, quanto ao método hormonal oral combinado, que vem a ser o mais utilizado, de acordo com a literatura.

Buscando através de investigações a presença de possíveis contraindicações que cada paciente venha a possuir, bem como, sanando suas dúvidas quanto aos possíveis efeitos adversos gerados, explicando a importância da adesão e do uso correto e as informando que em casos de aparecimento de efeitos colaterais, as mesmas devem buscar 
suporte profissional para melhor conduzi-las, evitando-se assim o agravamento e o abandono equivocado do método.

\section{REFERENCIAS}

ALMEIDA, A. P. F. D.; ASSIS, M. M. D. Efeitos colaterais e alterações fisiológicas relacionadas ao uso contínuo de anticoncepcionais hormonais orais. Revista Eletrônica Atualiza Saúde, v. 5, n. 5, p. 85-93, 2017.

BORGES, M. C. et al. Conhecimento sobre os efeitos dos contraceptivos hormonais por acadêmicas da saúde. Revista Baiana de Enfermagem, v. 30, n. 4, p. 1-11, 2016.

CABRAL, N. M. M. D. et al. Prevalência dos efeitos colaterais pelo uso de anticoncepcionais orais em estudantes de medicina de uma instituição privada. Anais da Faculdade de Medicina de Olinda, v. 2, n. 2, p. 28, 2018.

COUTO, P. L. S. et al. Evidências dos efeitos adversos no uso de anticoncepcionais hormonais orais em mulheres. Enfermagem em Foco, v. 11, n. 4, p. 79-86, 2020.

FINOTTI, M. Manual de Anticoncepção. Federação Brasileira das Associações de Ginecologia e Obstetrícia (FEBRASGO), São Paulo: FEBRASGO, 2015.

HAERTEL, J. C. et al. Saberes e práticas sobre o uso do contraceptivo hormonal oral por mulheres em idade fértil. Journal of Nursing and Health, v. 10, n. 1, p. 1-21, 2020.

LIMA, A. C. S. et al. Influência de anticoncepcionais hormonais e ocorrência de acidente vascular cerebral: revisão integrativa. Revista Brasileira de Enfermagem, v. 70, n. 3, p. 675-683, 2017.

LUZ, A. L. R. et al. Métodos contraceptivos: Principais riscos e efeitos adversos. Revista de Casos e Consultoria, v. 12, n. 1, p. 1-17, 2021.

OLIVEIRA, K. A. R. D.; SATO, M. D. O.; SATO, R. M. S. Uso e conhecimento a respeito de anticoncepcionais por acadêmicas de farmácia. Revista UNIANDRADE, v. 20, n. 3, p. ,115120, 2019.

RIBEIRO, C. C. M. Efeitos dos diferentes anticoncepcionais hormonais nos valores de pressão arterial da mulher. Revista Brasileira de Enfermagem, v. 71, n. 3, p. 1537-1543, 2018.

SANTOS, A. C. N. D. et al. Proteína C Reativa em Usuárias de Contraceptivo Oral: Fatores Relacionados e Risco Cardiovascular. International Journal of Cardiovascular Sciences, v. 29, n. 4, p. 320-325, 2016.

SILVA, C. V. D. Histórias de utilização de pílulas anticoncepcionais no brasil, na década de 1960. Tese (Doutorado). Fundação Oswaldo Cruz (FMO). Instituto Nacional de Saúde da Mulher, da Criança e do Adolescente Fernandes Figueira, 2017. Disponível em: <https://www.arca.fiocruz.br/bitstream/icict/25248/2/cristiane_silva_iff_mest_2017.pdf>. Acesso em: 30 mar. 2021. 